\title{
Remote sensing of sunlight-induced chlorophyll fluorescence and reflectance of Scots pine in the boreal forest during spring recovery
}

\author{
Juliette Louis ${ }^{\mathrm{a}, *}$, Abderrahmane Ounis ${ }^{\mathrm{a}}$, Jean-Marc Ducruet ${ }^{\mathrm{a}}$, Sébastien Evain ${ }^{\mathrm{a}}$, Tuomas Laurila ${ }^{\mathrm{b}}$, \\ Tea Thum ${ }^{\mathrm{b}}$, Mika Aurela ${ }^{\mathrm{b}}$, Gunnar Wingsle ${ }^{\mathrm{c}}$, Luis Alonso ${ }^{\mathrm{d}}$, Roberto Pedros ${ }^{\mathrm{d}}$, Ismaël Moya ${ }^{\mathrm{a}}$ \\ a Laboratoire pour l'Utilisation du Rayonnement Electromagnétique (LURE) - CNRS, Univ. Paris-Sud, Bât. 203-BP34, 91898 Orsay, France \\ ${ }^{\mathrm{b}}$ Finnish Meteorological Institute (FMI), Climate and Global Change Research, Sahaajankatu 20E, FIN-00880, Helsinki, Finland \\ ${ }^{\mathrm{c}}$ Agricultural University, Department of Forest Genetics and Plant Physiology, SLU, SE-901 83 Umeå, Finland \\ ${ }^{\mathrm{d}}$ Universitat de València- Avda. Blasco Ibáñez, 13. 46010 València, Spain
}

Received 17 September 2004; received in revised form 26 January 2005; accepted 29 January 2005

\begin{abstract}
A measurement campaign to assess the feasibility of remote sensing of sunlight-induced chlorophyll fluorescence (ChlF) from a coniferous canopy was conducted in a boreal forest study site (Finland). A Passive Multi-wavelength Fluorescence Detector (PMFD) sensor, developed in the LURE laboratory, was used to obtain simultaneous measurements of ChlF in the oxygen absorption bands, at 687 and 760 $\mathrm{nm}$, and a reflectance index, the PRI (Physiological Reflectance Index), for a month during spring recovery. When these data were compared with active fluorescence measurements performed on needles they revealed the same trend. During sunny days fluorescence and reflectance signals were found to be strongly influenced by shadows associated with the canopy structure. Moreover, chlorophyll fluorescence variations induced by rapid light changes (due to transient cloud shadows) were found to respond more quickly and with larger amplitude under summer conditions compared to those obtained under cold acclimation conditions. In addition, ChlF at 760 nm was observed to increase with the chlorophyll content. During this campaign, the $\mathrm{CO}_{2}$ assimilation was measured at the forest canopy level and was found remarkably well correlated with the PRI index.
\end{abstract}

(C) 2005 Elsevier Inc. All rights reserved.

Keywords: Boreal forest; Sunlight-induced chlorophyll fluorescence; $\mathrm{CO}_{2}$ flux; Diurnal cycle; Oxygen absorption band; Passive remote sensing; FLD principle; PRI; Scots pine

Abbreviations: APAR; Absorbed photosynthetically active radiation; Chl; Chlorophyll; FIPAM; Frenquency induced pulse amplitude modulation; FLD; Fraunhofer line discriminator; Fo; minimum yield of Chl a fluorescence in dark-adapted needles; Fm; maximum yield of $\mathrm{Chl}$ a fluorescence in dark adapted needles; Fm'; maximum yield of Chl a fluorescence in the presence of PAR; Fs; stationary Chl fluorescence flux; $\mathrm{Fv} / \mathrm{Fm}$; maximum photochemical yield of PSII; $\Delta \mathrm{F} / \mathrm{Fm}$ '; effective photochemical yield; LHCII; Light harvesting antenna of photosystem II; Lidar; Light detection and ranging; NDVI; Normalized difference vegetation index; NPQ; Non-photochemical quenching; PAR; Photosynthetically active radiation; PMFD; Passive multi-wavelength fluorescence detector; PRI; Physiological reflectance index (also called Photochemical Reflectance Index); PSI; Photosystem I; PSII; Photosystem II; $\mathrm{Q}_{\mathrm{A}}$; primary quinone acceptor.

* Corresponding author. Tel.: +331644682 72; fax: +33164468006

E-mail address: Juliette_louis@uqtr.ca (J. Louis).

\section{Introduction}

The boreal forest, composed of evergreen (pine and fir) and deciduous (birch and aspen) trees, contributes significantly to carbon fluxes since it is the largest forest of the northern hemisphere. Most conifers retain their needles for several years. Thus cold acclimation processes have been developed, that facilitate survival in severe freezing periods, sometimes combined with high light levels. Earlier studies performed at the needle level have shown that conifers in cold climates experience large seasonal changes in photosynthetic activity. They exhibit a gradual decline during late summer and autumn, a strong inhibition during winter, and a complete recovery during spring. A study of the carotenoid composition of the 
needles over different seasons (Adams III \& DemmigAdams, 1994) evidenced a higher level of lutein and xanthophyll cycle carotenoids, and a lower level of $\alpha$ carotene, in winter compared to summer. In addition, the extent of the de-epoxidation of violaxanthin to antheraxanthin and zeaxanthin at midday was greater during the winter. These results were confirmed by Ottander et al. (1995) who also measured a decrease of the content of D1-protein, LHCII proteins and chlorophyll, which occurred before the increase of the xanthophyll cycle carotenoids pool and the change of the epoxidation state. After a substantial drop in October, the chlorophyll content remained fairly constant at a $40 \%$ loss, on a needle area basis. Adams III and Demmig-Adams (1994) and Ottander et al. (1995) also evaluated the maximum electron transfer rate of PSII using the chlorophyll fluorescence parameters $(\mathrm{Fv} / \mathrm{Fm})$ that dropped sharply in winter with a minimum in February. Ottander et al. (1995) suggested that a major reorganisation of the light-harvesting complexes occurs during the winter, allowing an increase of energy dissipation as heat. PSI photochemistry was less inhibited during winter, at variance with PSII. Ivanov et al. (2001) showed in Scots pine that cyclic electron transfer around the PSI was enhanced, as well as the intersystem and stromal electron pool size, which could play a role in spring recovery. For a general overview on evergreen plants, see Öquist and Huner (2003).

Other overwintering evergreen species may also exhibit important Chl-protein changes after cold acclimation. Gilmore and Ball (2000) evidenced a new spectral component around $715 \mathrm{~nm}$ in the low temperature (77 $\mathrm{K}) \mathrm{Chl}$ fluorescence emission spectrum of leaves of winter-acclimated snow gum (Eucalyptus pauciflora Sieb. ex Spreng.). This component seemed to be associated with some conformational change of the PSII Chl proteins that overrides the necessity of a $\mathrm{pH}$ gradient. Interestingly, a decrease in $\mathrm{F}_{\mathrm{V}} / \mathrm{F}_{\mathrm{M}}$ down to 0.2 after cold acclimation was also observed in this species whereas a normal value of 0.8 was recovered after the end of cold acclimation.

Recently, new instruments have been developed for passive remote sensing of sunlight-induced chlorophyll fluorescence. These instruments allow the contribution of chlorophyll fluorescence to the spectral radiance emerging from the vegetation to be determined. They are based on the Fraunhofer line principle initially proposed by Plascyk for the H $\alpha$ line (Plascyk, 1975; Plascyk \& Gabriel, 1975). The extension of this method to the atmospheric oxygen absorption bands has been achieved by Moya et al. (1998, 2004), who described an instrument that measures sunlight-induced chlorophyll fluorescence at $760 \mathrm{~nm}$, at a distance of several meters. Furthermore, the same instrument is able to monitor the PRI index (Evain et al., 2004) simply by changing the interference filters. This index, defined as the relative changes of the reflectance at 531 $\mathrm{nm}$ relative to that at $570 \mathrm{~nm}$ (Gamon et al., 1990) correlates well with changes of non-photochemical quenching of chlorophyll fluorescence (Demmig-Adams \& Adams, 1992; Evain et al., 2004; Niyogi, 1999).

In order to obtain a more complete characterization of vegetation response, a new Passive Multi-wavelength Fluorescence Detector (PMFD) instrument, measuring fluorescence and reflectance at $760 \mathrm{~nm}$ and at $687 \mathrm{~nm}$, together with the Physiological Reflectance Index (PRI), was used for the measurement campaign described here. The instrument is described in (Evain et al., 2001). The campaign was conducted in the boreal forest at Sodankyla (Finland) during the period corresponding to the transition of pine trees from a winter dormant state to a summer fully active state of photosynthesis (Öquist \& Huner, 2003). The campaign, supported by the European Space Agency (ESA), was aimed at assessing the feasibility of measurement of sunlight-induced chlorophyll fluorescence at the canopy level in the boreal forest. Furthermore, passive fluorescence and reflectance signatures, extracted from these data, were compared and contrasted with the evolution of the fluorescence parameters at the needle level. These parameters were measured continuously and at a distance, using a micro-lidar. The data collected were correlated with the net $\mathrm{CO}_{2}$ uptake at the forest level. These measurements were also complimented by the determination of pigment content, once a week.

The results obtained show a strong influence of the canopy structure and of the shadows on the measurements performed during the sunny days, when direct illumination predominated. Nevertheless, the measurement of fluorescence at the two wavelengths proved to be feasible. Both fluorescence quantum yields at $760 \mathrm{~nm}$ (ФF760) and at 687 $\mathrm{nm}($ (F687) were positively correlated with PAR. Under constant illumination, an increase of $\Phi F 760$ was observed which paralleled the increase of chlorophyll content, while ФF687 stayed almost constant. Furthermore, the PRI index appeared to be well correlated to the $\mathrm{CO}_{2}$ assimilation during spring recovery.

\section{Materials and methods}

\subsection{Plant material and experimental site}

The campaign took place at the Arctic Research Center of the Finnish Meteorological Institute, near Sodankyla, Finland (26 $36^{\circ}$ longitude East, $67^{\circ} 22^{\prime}$ latitude North), from 23 April 2002 to 10 June 2002. The Research Centre is located in a Scots pine forest, naturally generated after forest fires. The average tree age is 103 years. The height of these trees is about $10 \mathrm{~m}$, with a diameter of about 0.1 $\mathrm{m}$. The tree density is 210,000 trunks per $\mathrm{km}^{2}$ and the ground vegetation is $73 \%$ lichens, $12 \%$ mosses, and $15 \%$ small shrubs. The soil type of the forest is fluvial sandy podzol. 


\subsection{Passive fluorescence measurements}

Solar-induced fluorescence was measured at the canopy level with the Passive Multi-wavelength Fluorescence Detector (PMFD), see Evain et al. (2001). This instrument is based on the Fraunhofer line principle (Plascyk, 1975; Plascyk \& Gabriel, 1975), applied in the atmospheric oxygen $\mathrm{A}$ and $\mathrm{B}$ absorption bands (760 and $687 \mathrm{~nm}$, respectively). This method compares the depth of an absorption band in the incident solar irradiance to the depth of this band in the radiance of the target, in order to estimate the in-filling of the band by the chlorophyll fluorescence emission. This requires a measurement of the radiances reflected by the target within and out of the band (Fig. 1). As the depth and the shape of the atmospheric oxygen absorption bands depend on the path length of solar radiation, it is necessary to compare these radiances with those of a reference panel situated in the same light regime (Moya et al., 2004). The heart of the PMFD is a rotating filter-holder wheel, equipped with six interference filters (Omega Optical, Brattleboro, VT, USA), in front of a detector (Fig. 2). Two filters are devoted to the measurement of the atmospheric oxygen absorption band around $760 \mathrm{~nm}$ (A band), as described in Moya et al. (2004). The radiant flux out of the band is measured with an interference filter located at $758.3 \mathrm{~nm}$ $(\mathrm{FWHM}=1.6 \mathrm{~nm})$, whereas the flux in the band is determined by a filter located at $760.6 \mathrm{~nm}(\mathrm{FWHM}=1.3$ $\mathrm{nm})$. Two other filters are devoted to the measurement of the atmospheric oxygen absorption band around $687 \mathrm{~nm}$ (B band). The radiant flux out of the band is determined at $686.2 \mathrm{~nm}(\mathrm{FWHM}=0.8 \mathrm{~nm})$, whereas the flux in the band is determined at $687.3 \mathrm{~nm}(\mathrm{FWHM}=0.7 \mathrm{~nm})$. In addition, two band-pass interference filters $(\mathrm{FWHM}=10$ $\mathrm{nm}$, transmission 70\%) were used to measure the reflectance signals at 531 and $570 \mathrm{~nm}$, respectively. A long-pass filter (Schott KV500) was used to cut-off the UV radiation at the entrance of the sensor. A flip-flop mirror, moved by a magnet, directs the field of view of the instrument, after one revolution of the filter-wheel, alternatively towards the vegetation target or to a reference board, as described in Moya et al. (2004). The repetition period of the measurement was set to $2 \mathrm{~s}$. The

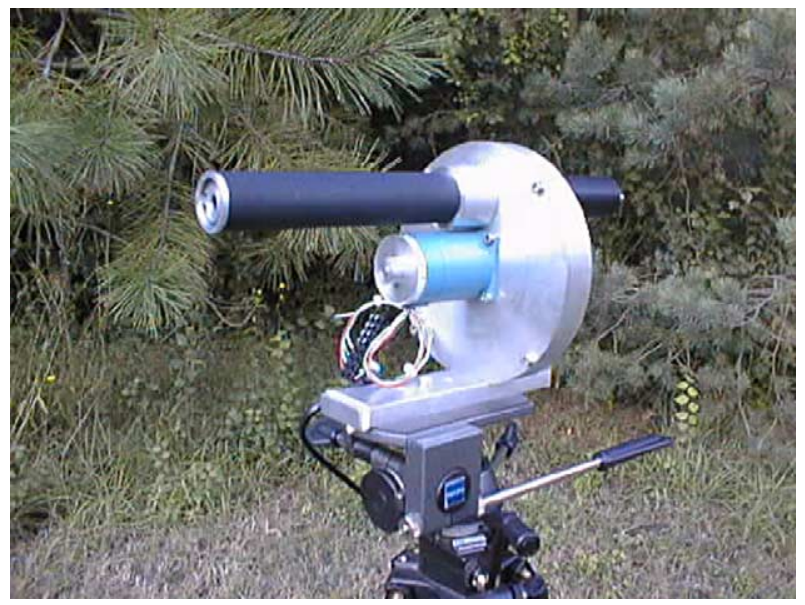

Fig. 2. Photograph of the Passive Multi-Wavelength Fluorescence Detector (PMFD).

fluorescence fluxes are calculated according to the following relations (Moya et al., 2004):

$R=(a-b) /(c-d)$

$F=b-R d$

$R$ and $F$ are respectively the calculated reflectance and stationary fluorescence flux. $a$ and $b$ represent the detected radiances from the reference panel in and out of the oxygen absorption band, respectively. Similarly, $c$ and $d$ represent the detected radiances from the target in and out of the band (Fig. 1). These relationships were applied at $687 \mathrm{~nm}$ and at $760 \mathrm{~nm}$. The parallel measurements of reflectance signals in the red and near infrared spectral range allow the calculation of a NDVI-like index (Tucker, 1979) using the relation:

$\mathrm{NDVI}=\left(R_{760}-R_{687}\right) /\left(R_{760}+R_{687}\right)$

The PMFD sensor was installed on the top of a $20-\mathrm{m}$ height tower and maintained in the same viewing direction during the entire campaign. The zenith angle of the viewing direction was about 120 degrees and the instrument was oriented south-to-north at a $50 \mathrm{~m}$ distance from the target. The field of view was $70 \mathrm{mrad}$ and the spot covered $9 \mathrm{~m}^{2}$, which corresponded approximately to three trees. The PMFD automatically and continuously acquired the radi-
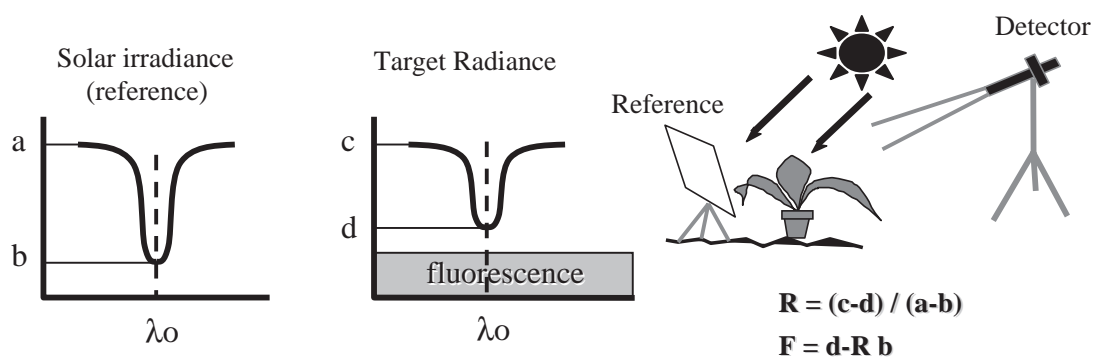

Fig. 1. Fraunhofer Line Discriminator principle. The method is based on the partial in-filling of the absorption band by the sun-induced emission of the luminescent target. $R$ and $F$ are the calculated reflectance and stationary fluorescence flux. 
ance signals from the forest canopy, with a period of $2 \mathrm{~s}$. A flip-flop mirror alternatively oriented the sensor field of view towards the target and a small reference panel installed horizontally near the instrument. The reference panel was a white PVC panel, previously calibrated against a standard white lambertian diffuser (Spectralon, Labsphere, USA). The reflectance and fluorescence calculated in this way are bi-directional, with a fixed detection direction and a variable incident direction. All the curves plotted are presented without any smoothing.

\subsection{PRI measurements}

According to Gamon et al. (1990), measurements of reflectance at 531 and $570 \mathrm{~nm}$ enable the PRI index to be monitored, in parallel to fluorescence, with the same field of view and on the same target:

$\mathrm{PRI}=\frac{R_{531}-R_{570}}{R_{531}+R_{570}}$

The calculation of the reflectance is simpler:

$R_{531}=t_{531} / r_{531}$

$R_{570}=t_{570} / r_{570}$

$t_{531}$ and $r_{531}$ are the radiance signals from the target and from the reference, respectively. In this definition, the contribution of blue-green fluorescence has been neglected. Laboratory measurements showed indeed that this contribution is less than $0.1 \%$ (Juliette Louis, unpublished results).

PRI was also measured in parallel with an ASD FieldSpec Pro FR Spectroradiometer, bundled to an optical fibre for light collection, with a field of view of $17.5 \mathrm{mRad}$. The optical fibre was directed alternatively towards a Spectralon panel and the same target as the PMFD. The signal from the target was divided by the signal from the reference panel in order to determine the bi-directional reflectance of the tree canopy.

\subsection{Atmospheric correction}

As the target was $50 \mathrm{~m}$ distant from the instrument and from the reference panel, the atmospheric absorption of the radiance signals had to be taken into account. The absorption at $760.5 \mathrm{~nm}$ (within the band) over $50 \mathrm{~m}$ of a horizontal path was calculated with a radiative transfer code, MODTRAN 4. It was concluded that the apparent radiance at $760.5 \mathrm{~nm}$ had to be multiplied by a correction factor of 1.07 , to account for the attenuation of the air mass between the target and the instrument. The attenuation for the other radiance signals proved to be negligible.

\subsection{Active fluorescence measurements}

The micro-Lidar FIPAM (Apostol et al., 2001; Flexas et al., 2000) has been used to monitor laser-induced Chl fluorescence. The excitation beam was produced by a pulsed laser diode $(665 \mathrm{~nm}, 4 \mu \mathrm{s}$ pulsewidth, $300 \mathrm{~mW}$, Philips, Issy-les-Moulineau, France). The frequency of modulation can be varied from 0.5 to $100 \mathrm{kHz}$. Chlorophyll fluorescence was detected by a PIN photodiode after it passed through a long-pass filter (RG 9, $1 \mathrm{~mm}$, Schott, Clichy, France). The signal was processed by specially designed electronics, which make the detector insensitive to continuous illumination. The stationary fluorescence signal (Fo during the night, Fs, during the day) is measured in a non-actinic way, at a frequency $<100 \mathrm{~Hz}$ depending on the ambient light. The maximum $\mathrm{Chl}$ fluorescence level (Fm during the night, Fm' during the day) is obtained by increasing the frequency of excitation up to $100 \mathrm{kHz}$. At this frequency, the resulting excitation intensity is about 4000 $\mu \mathrm{mol}$ photons $\mathrm{m}^{-2} \mathrm{~s}^{-1}$. The measurement of $\mathrm{Fm}$ is repeated at a frequency, which also depends on the ambient light. During the night, Fo is measured every $6 \mathrm{~s}$ and Fm every hour. The measured fluorescence parameters allow the maximum photochemical yield $(\mathrm{Fv} / \mathrm{Fm}=(\mathrm{Fm}-\mathrm{Fo}) / \mathrm{Fm})$, the actual photochemical yield $\left(\Delta \mathrm{F} / \mathrm{Fm}{ }^{\prime}=\left(\mathrm{Fm}{ }^{\prime}-\mathrm{Fs}\right) / \mathrm{Fm}{ }^{\prime}\right)$ and the non-photochemical quenching $(\mathrm{NPQ}=(\mathrm{Fm}-\mathrm{Fm})$ Fm')) to be deduced. The FIPAM was fixed on a tripod installed on the ground, oriented south-to-north at a distance of $2.5 \mathrm{~m}$ from a small pine tree. The needles of a small branch were oriented vertically, fixed by a clamp. The laser spot, which covered a surface of $20 \times 3 \mathrm{~mm}$, illuminated several needles. The measurements were carried out continuously. Needle temperature was measured by a small thermocouple in contact with the back of the same needles used for fluorescence measurements. Air temperature was measured by an identical thermocouple placed near the needles but protected from direct radiation and wind. A quantum-meter oriented perpendicularly to the plane of the needles was used to measure the incoming PAR. All the environmental parameters were acquired immediately after each fluorescence measurement.

The maximum photochemical yield of Scots pine needles was also measured on dark-adapted needles with a Plant Efficiency Analyzer (PEA Hansatech), a portable fluorometer. Saturating illumination is provided by light emitting diodes having a peak emission at $650 \mathrm{~nm}$. The fluorescence parameter $\mathrm{Fv} / \mathrm{Fm}$ is automatically calculated by the instrument. Measurements with the PEA were performed daily, at three different sites.

\subsection{Pigment analysis}

Needles were collected once a week from April 23 to June 11. Ten needles were collected between 9:00 and 11:00 a.m., preserved in liquid-nitrogen while transferred to the laboratory for pigment extraction. Fresh weight contents of chlorophyll a and $b$, antheraxanthin, zeaxanthin, violaxanthin, lutein, neoxanthin and alfa and beta-carotenes were obtained. Pigment analysis was conducted using HPLC at the Swedish Agricultural University in Umeå. 


\section{7. $\mathrm{CO}_{2}$ fluxes measurements}

The eddy-covariance fluxes of $\mathrm{CO}_{2}, \mathrm{H}_{2} \mathrm{O}$, heat, momentum and meteorological state were measured using a LICOR-7000 analyser and a SATI-3Sx sonic anemometer at $23 \mathrm{~m}$ above the ground. The eddy-covariance methodology has been described by Aurela et al. (2001, 2002). In addition, heat and momentum fluxes were measured using four Solent sonic anemometers at 47, 32, 8 and $3 \mathrm{~m}$. All these measurements were conducted by the Finnish Meteorological Institute.

\section{Results}

\subsection{Daily variations: active fluorescence measurements}

Continuous measurements were performed with the FIPAM during the entire campaign, producing a time series of the stationary fluorescence, $\mathrm{Fv} / \mathrm{Fm}$ and $\Delta \mathrm{F} / \mathrm{Fm}$ '. Although these measurements were taken from one tree, at the needle level, they were used for comparison with the passive measurements. Fig. 3 shows diurnal cycles of chlorophyll fluorescence under two extreme light conditions. Regularly spaced spikes in the Fs signal during the night are due to influence of some of reduced $\mathrm{Q}_{\mathrm{A}}$ still present $6 \mathrm{~s}$ after a saturating pulse at $100 \mathrm{kHz}$. During sunny days, Fs experienced a 35\% decrease at midday compared to the early morning values, Fm' a $70 \%$ decrease (Fig. 3A) and $\Delta \mathrm{F} / \mathrm{Fm}$ ' a $60 \%$ decrease (Fig. $3 \mathrm{~B})$. Fs decreased even below the Fo level around midday. The fall of Fs and Fm around 4:00 a.m. was not due to a fluorescence decrease but to an optical problem, caused by water condensation in the optics of the instrument. This phenomenon was observed at predawn on cloudless nights. Under low light conditions (Fig. 3C,D), Fs stayed fairly constant along the day and the decrease of Fm' and $\Delta \mathrm{F} /$ Fm' was less pronounced.

\subsection{Daily variations: passive measurements}

Radiance signals will be described prior to fluorescence signals since fluorescence is extracted from the comparison of radiance signals from the target and a reference. Fig. 4 shows a diurnal cycle of radiance signals recorded when direct illumination predominated. The intensity of the reference signal, measured on a flat panel, depends on the air mass and on the angle between the sun and the panel. The panel and the quantum-meter were both horizontal. The diurnal cycle variation of the PAR signal showed a regular bell-shaped curve for this sunny day, with a maximum at local midday (14:00). Whatever the wavelength considered, the reference signals also showed a regular bell-shaped curve as was expected, in agreement with MODTRAN modeling (not shown), but shifted in time. This shift between the maxima is attributed to a small difference in the horizontal orientation settings of the quantum-meter compared to the reference panel.


Fig. 3. Diurnal cycle variations of the PAR and of the fluorescence parameters measured by the FIPAM. High light conditions (28 May 2002): (A) The FIPAM measures Fo and Fm during the night, Fs and Fm' during the day. Fs and Fm decrease when the PAR increases and reaches a minimum around noon. Thereafter they both increase as the PAR decreases. (B) Fv/Fm is measured during the night, $\Delta \mathrm{F} / \mathrm{Fm}$ ' during the day. $\Delta \mathrm{F} / \mathrm{Fm}$ ' decreases strongly around noon. Low light conditions (22 May 2002): (C) Fs stays constant along the day, while Fm' decreases weakly when the PAR increases. (D) $\Delta F / F m$ ' decreases weakly when the PAR increases. 


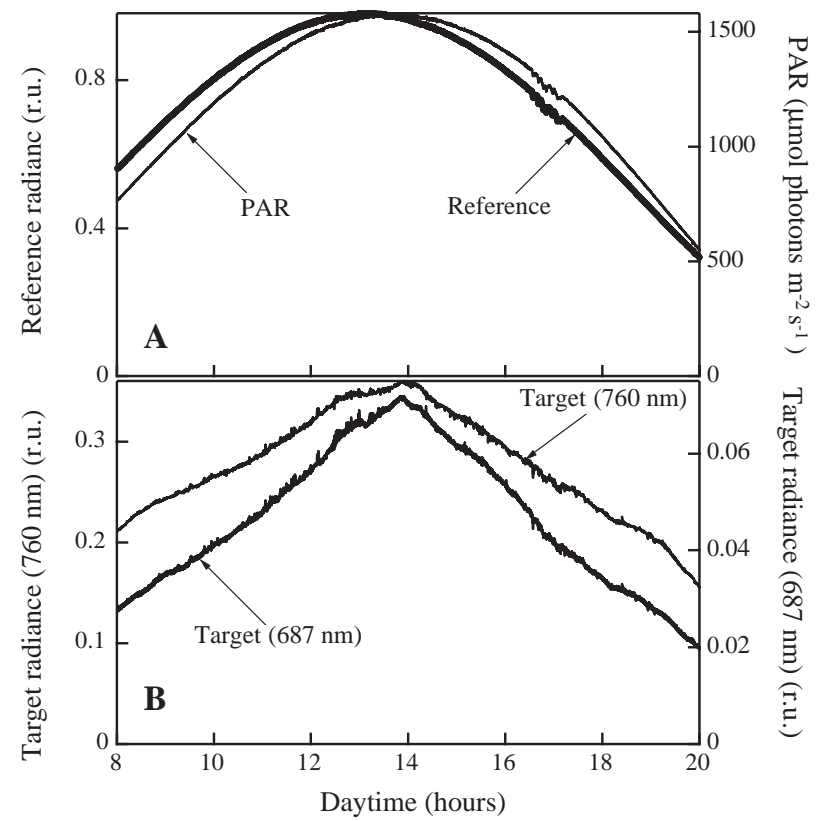

Fig. 4. Measurements performed by the PMFD under high light conditions (28 May 2002). (A) Comparison of the PAR with radiance from the reference panel. (B) Comparison between radiances from the target (trees), for two different wavelengths, 687 and $760 \mathrm{~nm}$. The reference panel and the quantum-meter were both horizontal (see text for more details).

Whatever the wavelength considered, the shapes of the target radiance signals were strongly different from those of the reference signals. All presented a peak around 14:00, less pronounced at $760 \mathrm{~nm}$ than at the other wavelengths. The shapes of the radiance signals at 530 and $570 \mathrm{~nm}$ (not shown) were similar to that of the signal at $687 \mathrm{~nm}$. In addition, patterns of irregularities of the target signals observed for all the sunny days contrasted with the very regular shape of the reference signals.

Fluorescence fluxes, calculated according to the relations stated previously, exhibited a similar time-dependence to that observed for the radiance signal at the same wavelengths (Fig. 5A). The fluorescence flux at $687 \mathrm{~nm}$ (F687) presented a more pronounced peak around 14:00 than at 760 $\mathrm{nm}$ (F760). F687 represented about 20\% of the flux reflected by the vegetation at this wavelength, while the fluorescence flux at $760 \mathrm{~nm}$ represented $2.5 \%$ of the reflected flux.

The comparison between passive and active measurements requires the calculation of relative fluorescence yields from passive data. The fluorescence fluxes depend on the fluorescence quantum yield $(\Phi s)$, on the intensity of the incident light (PAR), and on the amount of radiation intercepted and absorbed by the canopy (I).

$\Phi s(\lambda)=F s(\lambda) / \mathrm{APAR}$

where APAR is the absorbed incident light given as: APAR $=I \cdot$ PAR

However, it is difficult to estimate the amount of intercepted radiation by the canopy. Both PAR and reference radiances are measured from 2-dimensional surfaces, which do not reflect the complexity of a 3-dimensional canopy structure. We may assume that the radiance reflected by the vegetation, which takes into account the structure of the canopy, should be a good estimation of the intercepted fluxes. Six different radiance measurements were available but only the radiances at 531 and $570 \mathrm{~nm}$ had no appreciable fluorescence contribution. As the radiance at $531 \mathrm{~nm}$ depends on the non-photochemical quenching (see PRI results), we found out that the radiance reflected by the target at $570 \mathrm{~nm}$ was the most appropriate estimator of incident flux. Accordingly, we defined a relative fluores-

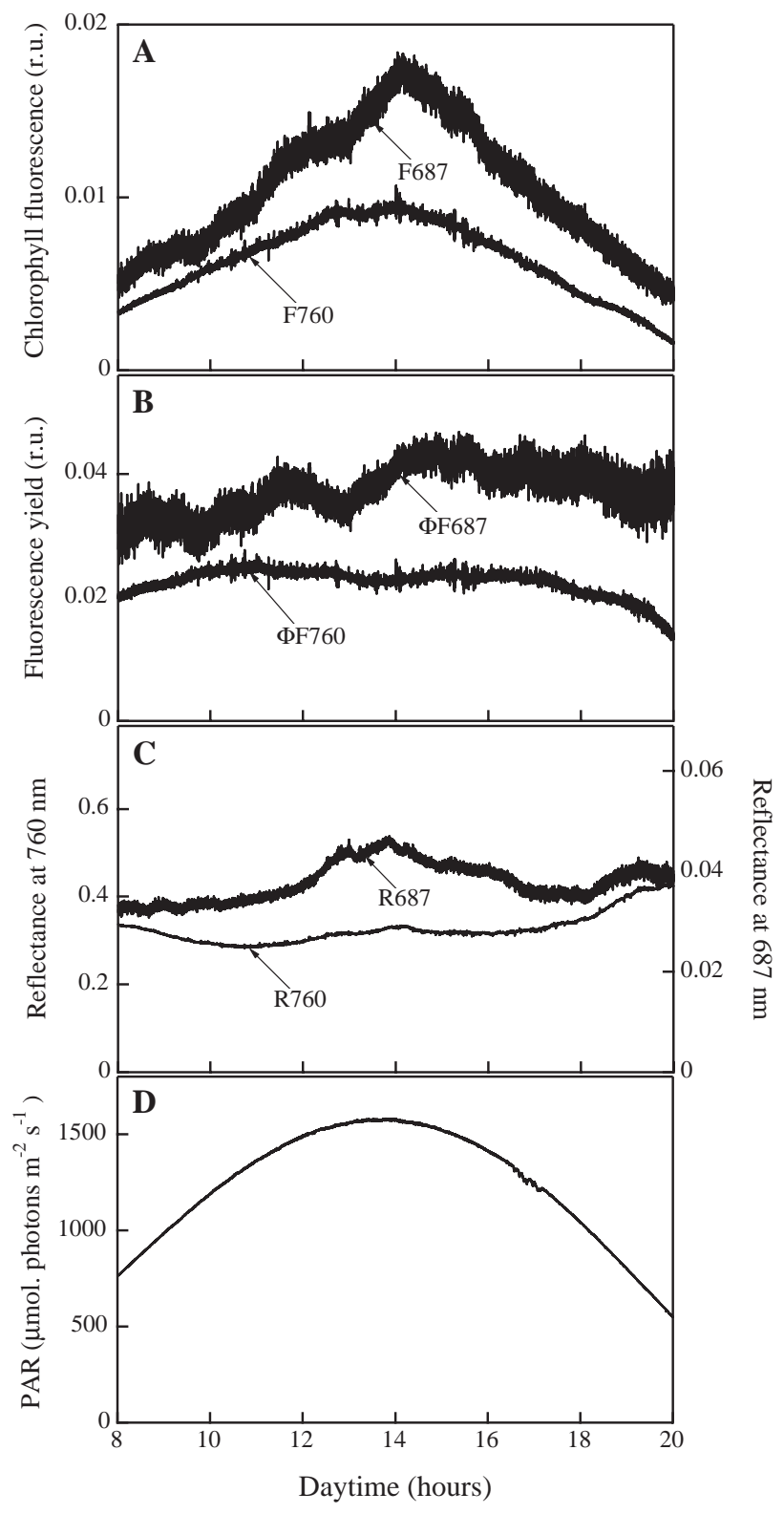

Fig. 5. Diurnal cycle variations of the PAR and of the fluorescence and reflectance measured by the PMFD for high light conditions (28 May 2002). (A) Fluorescence fluxes at 687 and $760 \mathrm{~nm}$. (B) Fluorescence yields at 687 and $760 \mathrm{~nm}$, obtained by dividing the fluorescence fluxes by the flux reflected by the target at $570 \mathrm{~nm}$. (C) Reflectance at $687 \mathrm{~nm}$ and $760 \mathrm{~nm}$. (D) PAR. 


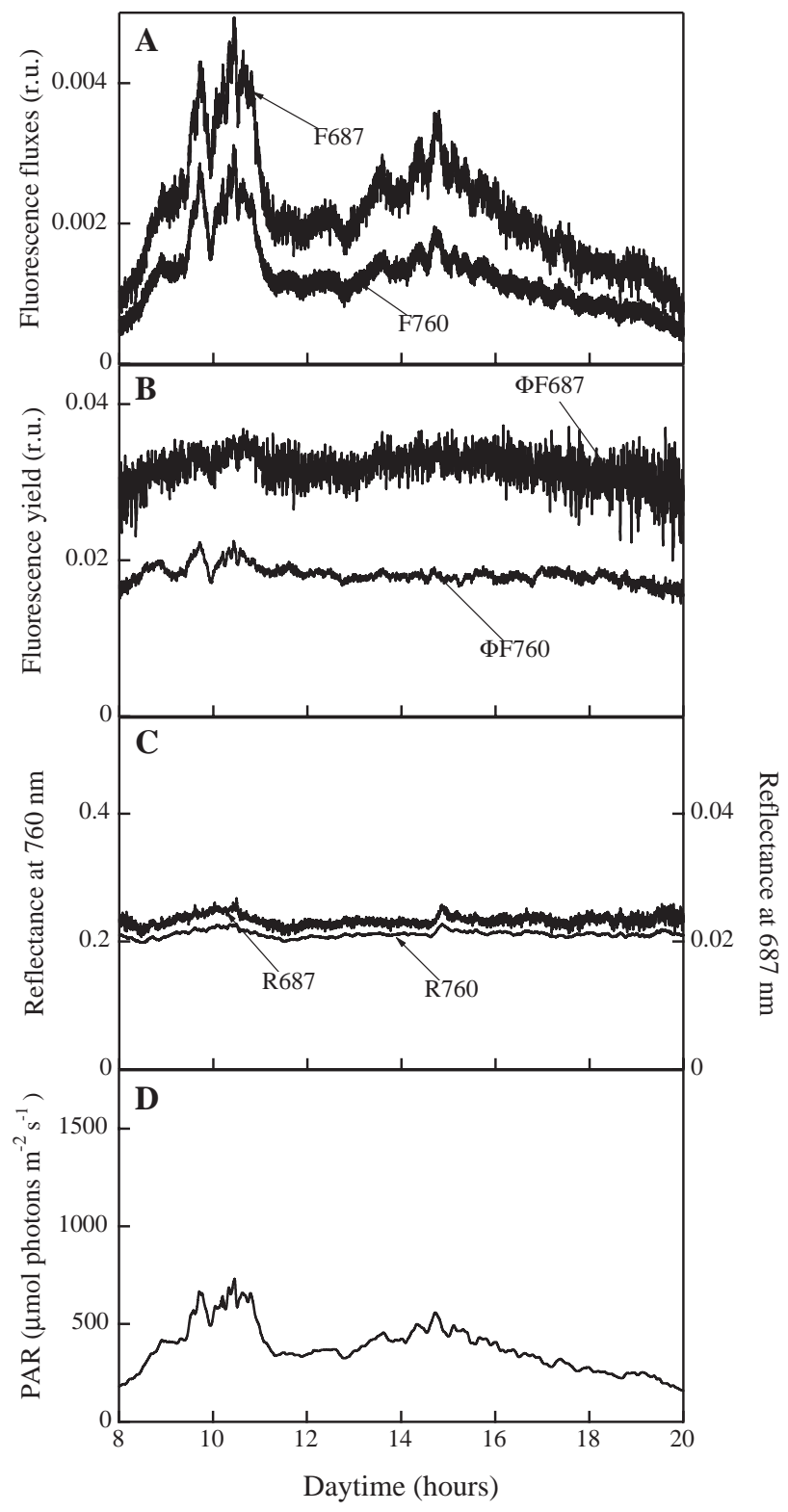

Fig. 6. Diurnal cycle variations of the PAR and of the fluorescence and reflectance measured by the PMFD for low light conditions (22 May 2002). (A) Fluorescence fluxes at 687 and $760 \mathrm{~nm}$. (B) Fluorescence yields at 687 and $760 \mathrm{~nm}$, obtained by dividing the fluorescence fluxes by the flux reflected by the target at $570 \mathrm{~nm}$. (C) Reflectance at 687 and $760 \mathrm{~nm}$. (D) PAR.

cence yield for each wavelength by dividing the fluorescence fluxes by the radiance reflected by the target at 570 nm, denoted by ФF687 and ФF760.

Fig. 5B shows that $\Phi F 687$ increased roughly from 8:00 to 20:00 local time, with a step transition after 14:00. In the same conditions, ФF760 stayed fairly constant. For the same day, the reflectance at $687 \mathrm{~nm}$ was close to $4 \%$ and the reflectance at $760 \mathrm{~nm}$ was close to $30 \%$ (Fig. 5C). One can observe that these bi-directional reflectances increased at midday in a more pronounced way at $687 \mathrm{~nm}$ than at $760 \mathrm{~nm}$.

When diffuse light dominated, all signals, including PAR and radiances, had a similar shape (data not shown). The fluorescence fluxes closely followed PAR variations (compare Fig. 6A and D). The fluorescence yields, ФF687 and ФF760, were parallel and almost constant (Fig. 6B). When the PAR increased above $400 \mu \mathrm{mol} \mathrm{m} \mathrm{m}^{-2} \mathrm{~s}^{-1}$, a slight increase of both yields was observed. The reflectance signals stayed constant over the day (Fig. 6C).

Fig. 7A shows a typical diurnal cycle of the PRI index together with the PAR. The variation was almost symmetric from morning to evening with a minimum around solar noon. Due to rapid succession of sun and shade periods, PRI variations were not clearly resolved except around 18:00 that day, when the transition is longer. Fig. 7B illustrates the response of PRI to PAR variations lasting several minutes. The PRI index is inversely correlated with PAR. A sudden transition lasting several minutes from full sunlight to overcast conditions induces an increase of PRI.

\subsection{Evolution of the signals during the campaign}

In order to follow the evolution of the signals during the campaign, time series have been generated by integrating the data between 11:00 and 15:00 local time for the fluorescence yields (Fig. 8A). Very cloudy days (PAR $<500$ $\mu \mathrm{mol}$ photons $\mathrm{m}^{-2} \mathrm{~s}^{-1}$ ) have been discarded.

One can observe that the daily integrated values of both ФF687 and ФF760 were positively correlated with the integrated PAR. ФF760 showed a greater dynamic range,
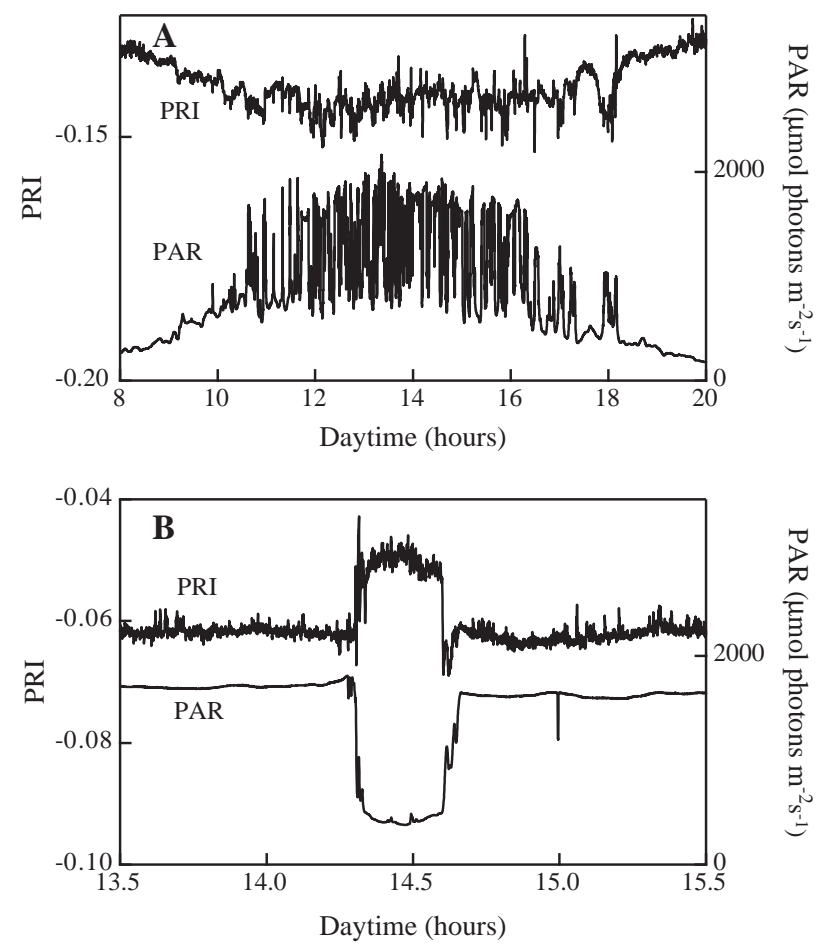

Fig. 7. (A) Typical diurnal cycle of the PRI index, measured by the PMFD, together with PAR (24 May 2002). (B) Decrease of the PRI index occurring after rapid transitions lasting several minutes from overcast to full sunlight (9 June 2002). 

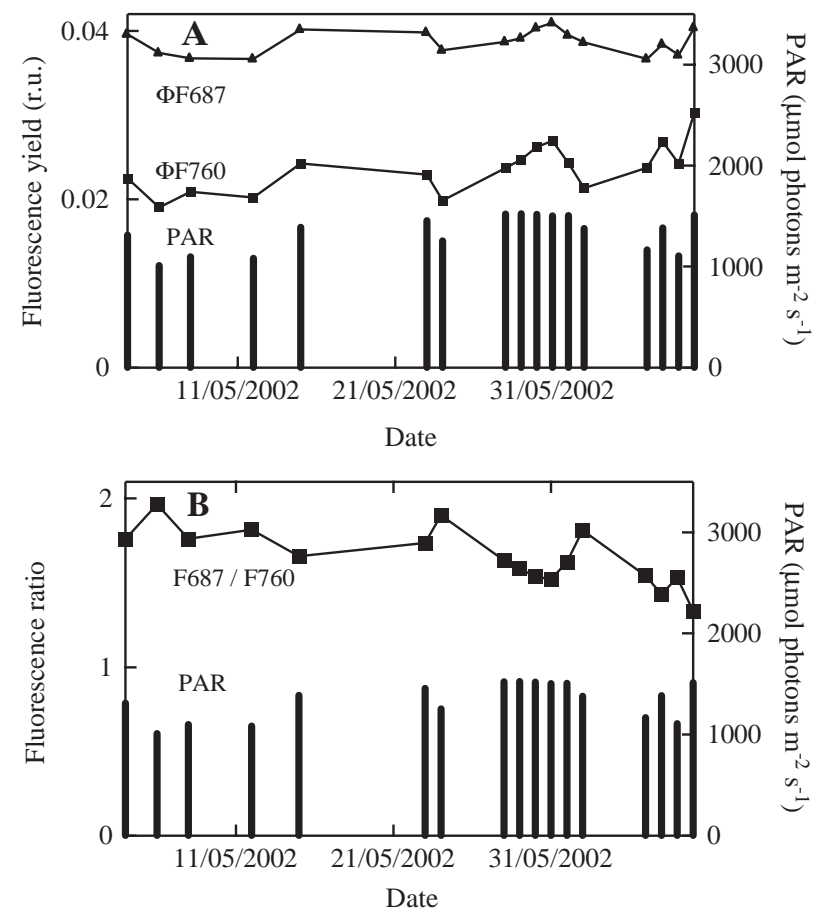

Fig. 8. (A) Time series of fluorescence yields and PAR integrated over $4 \mathrm{~h}$ around solar noon (14:00). Both yields were correlated with PAR (except for the sunny days at the end of May). $\$ 760$ increased at the end of the campaign whereas $\Phi 687$ stayed fairly constant. (B) Time series of the fluorescence ratio (F687 / F760).

with an increase at the end of the campaign, whereas $\Phi F 687$ stayed almost constant. As a result, the ratio of the integrated yields, $\Phi F 687 / \Phi F 760$ (=F687/F760), exhibited a continuous decrease more marked at the end of the campaign (Fig. 8B).

At the beginning of the campaign, on April 23-24, when there was still a continuous snow cover, negative net $\mathrm{CO}_{2}$ fluxes of about $-0.05 \mathrm{mg} \mathrm{m}^{-2} \mathrm{~s}^{-1}$ at noon were observed (Fig. $9 \mathrm{~A}, \mathrm{~B})$. The $\mathrm{CO}_{2}$ uptake by the canopy was already exceeding the total respiration. After June 2, the net $\mathrm{CO}_{2}$ fluxes at noon increased to $-0.4 \mathrm{mg} \mathrm{m}^{-2} \mathrm{~s}^{-1}$, which is a typical value in summer. A time series of net $\mathrm{CO}_{2}$ assimilation was generated and plotted with the time series obtained for the PRI (Fig. 10). The sign of net $\mathrm{CO}_{2}$ assimilation was changed so that the two signals could be compared. One can observe a good correlation between these signals as both remained almost constant until the end of May and then rose continuously up to the end of the campaign. The rise took place one day later for the net $\mathrm{CO}_{2}$ assimilation. The PRI calculated from the data obtained with the ASD radiometer gave the same steep increase at the end of the campaign (data not shown).

Time series were also generated using active fluorescence measurements averaged between 11:00 and 15:00. $\mathrm{Fv} / \mathrm{Fm}$ and $\Delta \mathrm{F} / \mathrm{Fm}$ ' were plotted for each day (Fig. 11). $\mathrm{Fv} / \mathrm{Fm}$ increased regularly during the whole period from 0.60 (6 May) to 0.80 (June). Independent measurements were made with the PEA instrument, starting from the beginning of April. At this date, Fv/Fm was below 0.2 and began to increase steeply at the end of April to reach 0.6 on the first week of May, which was in good agreement with the results obtained with the FIPAM (data not shown). $\Delta \mathrm{F} /$ Fm' was continuously measured with the FIPAM during May and June. Fig. 11 shows a negative correlation between $\Delta \mathrm{F} / \mathrm{Fm}$ ' and the averaged PAR. However, by selecting days having approximately the same low illumination (squares), one can observe a monotonic increase of the corresponding $\Delta \mathrm{F} / \mathrm{Fm}$ ' values. The same observation can be made when selecting high light days (circles).

Due to the high temporal resolution of the PMFD ( $2 \mathrm{~s})$, it was possible to compare fluorescence transients from full sunlight to cloudy conditions at the beginning and at the end of the campaign. Fluorescence yields were plotted versus PAR during short transition periods $(<1 \mathrm{~h})$ (Fig. 12A) during which the position of the sun could be considered almost constant. For clarity, a fit of the points is represented (Fig. 12B). In all cases fluorescence yield responded positively to PAR variations. The initial slope of these curves was calculated. Fig. 12C compares these fits for days at the beginning and at the end of the campaign. At $687 \mathrm{~nm}$, we observed a $27 \%$ increase of the initial slope, whereas the fluorescence yield level under full sunlight was unchanged, as already stated (Fig. 8). At $760 \mathrm{~nm}$, we observed a $42 \%$ increase of the initial slope. It is concluded that at both wavelengths the responsiveness of fluorescence yield to PAR variations is increased at the end of the campaign.

\subsection{Pigment content}

The total chlorophyll content remained almost constant except for a slight increase at the end of the period, whereas the Chlorophyll a/b ratio remained stable throughout the period (Table 1). A decrease of the carotenoid pool, more

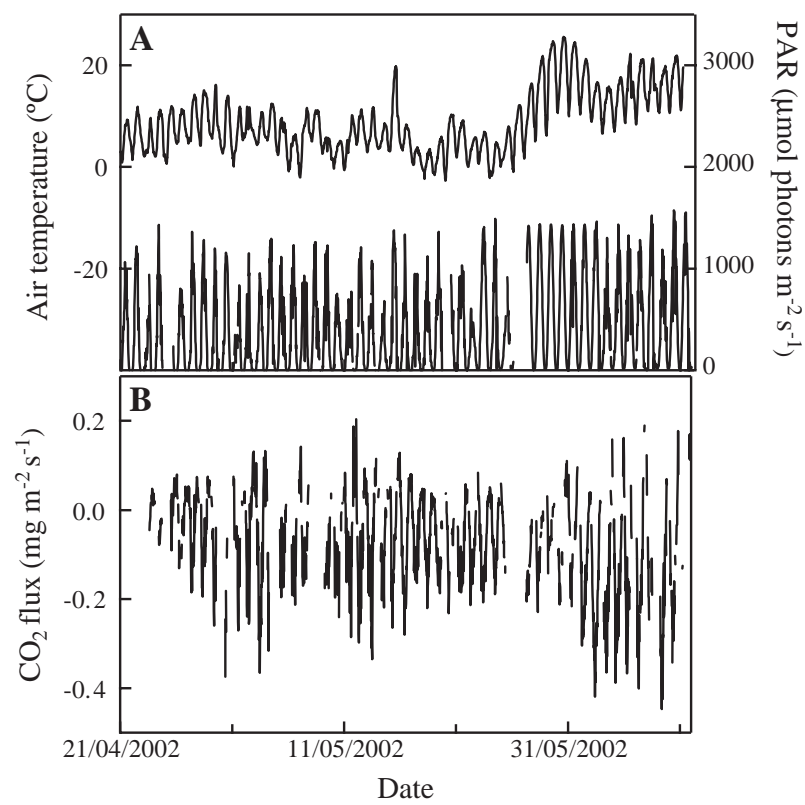

Fig. 9. (A) Air temperature (upper line) and PAR (lower line) on April 21June 11. (B) Half hourly net $\mathrm{CO}_{2}$ flux on April 21-June 11. A negative net $\mathrm{CO}_{2}$ flux indicates net uptake (flux downward) by the forest. 


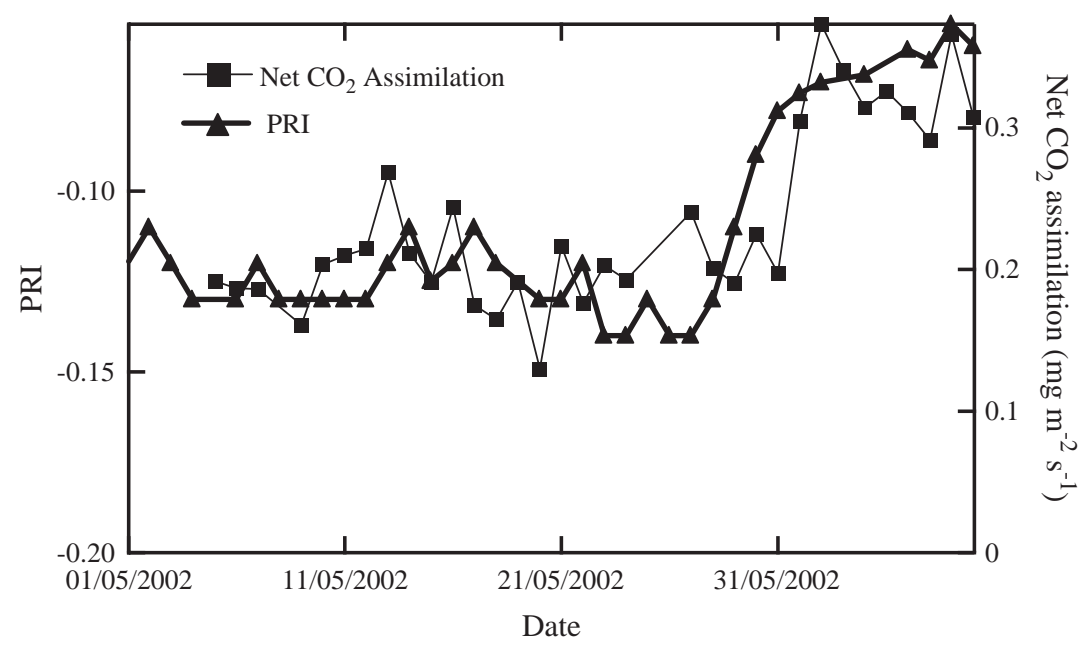

Fig. 10. Parallel plots of the PRI index and $\mathrm{CO}_{2}$ uptake time series during the campaign. Observe the parallel increase at the end of May.

pronounced for the lutein pigment, could be observed. These findings are in good agreement with data reported in the literature for the boreal forest (Ottander et al., 1995).

\section{Discussion}

A prominent feature is obvious in the radiance data (Fig. 4). The shape of the radiance signals measured with the PMFD on sunny days is very different according to whether they originate from the reference or from the target. This difference is attributed to a different light interception between the $3 \mathrm{D}$ canopy and the $2 \mathrm{D}$ reference panel. The peak around 14:00, observed for all of the sunny days, is probably ascribable to a Hot Spot effect (Hapke et al., 1996; Kuusk, 1985) as the inclination angles of the instrument and the sun were respectively $30^{\circ}$ and $42^{\circ}$, and the azimuthal angles were very close. The other irregularities could be due to a changing pattern of lighted and shadowed area of the tree canopy, when the direction of incident light changes. The sensitivity to the Hot Spot effect depends on the canopy reflection and transmission properties. At $687 \mathrm{~nm}$, the signal is strongly absorbed and will arise mostly from the top of the target, and so will be more sensitive to Hot Spot effect than the signal at $760 \mathrm{~nm}$, which is weakly absorbed and arises from scattering within the whole canopy. This may explain the more pronounced peak at $687 \mathrm{~nm}$ compared to $760 \mathrm{~nm}$. The structural origin of these effects is confirmed by the data obtained under diffuse illumination conditions. In this case, all the radiance signals, from the target and from the reference, can almost be superimposed, and depend only on PAR variations.

The fluorescence fluxes follow the same propagation laws and so have the same shape as the corresponding radiant fluxes (Fig. 5A). The calculation of fluorescence yields was expected to minimize canopy structure effects and to simplify the interpretation of canopy fluorescence emission. However, the diurnal cycles acquired on sunny days with active and passive techniques are quite different (Figs. 3A and 5B).

\subsection{Comparison of active and passive fluorescence measurements}

The diurnal cycles measured on sunny days by the FIPAM are characterized by a pronounced decrease of Fs, under high light conditions, to a level lower than Fo (Fig. $3 \mathrm{~A})$. This decrease is attributed to the increase of the nonphotochemical quenching (NPQ), calculated as stated above, which reached 2.5 at midday (not shown). This behaviour indicates that the plant was undergoing a strong constraint. As the campaign took place just after the snow melting period, a water deficit seems unlikely, so the reversible NPQ during the daily cycle is attributed to excess light.

At variance with Fs measured with the FIPAM, the diurnal cycles of both ФF687 and ФF760 recorded by the



Fig. 11. Evolution of the PAR and of the maximal and effective photochemical yields during the campaign, measured by the FIPAM. The circles and the squares highlight the increase of $\Delta \mathrm{F} / \mathrm{Fm}$ ' for the same PAR. Squares correspond to a PAR of about $200 \mu \mathrm{mol}$ photons $\mathrm{m}^{-2} \mathrm{~s}^{-1}$, circles to a PAR of about $1000 \mu \mathrm{mol}$ photons $\mathrm{m}^{-2} \mathrm{~s}^{-1}$. 
PMFD for the same days do not show any decrease of $\Phi F$ at midday. This is interpreted as a very moderated contribution of NPQ. These discrepancies may arise from differences in the target structure. In the case of the active measurements, the needles are fixed, oriented towards the south, homogeneously and continuously illuminated, especially around solar noon. These unusual conditions probably generate the observed strong NPQ. In the case of passive measurements, the target is composed of several trees. Needles inside the canopy are shadowed by other needles or stems, either permanently or flickeringly. As a result, the average intensity they receive is lower and probably not sufficient to induce a detectable non-photochemical quenching effect. Only the permanently sun-exposed needles undergo a strong
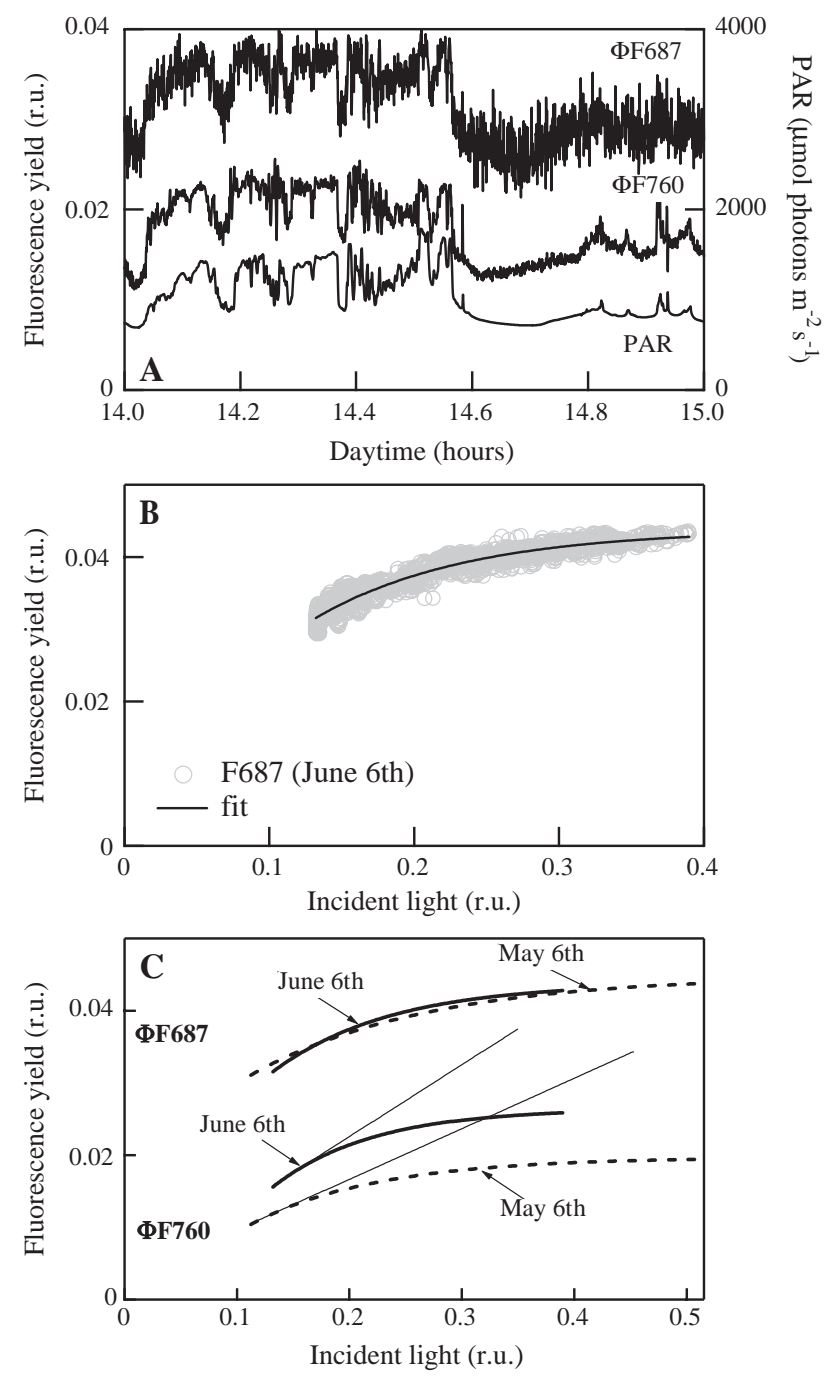

Fig. 12. Dynamical study of fluorescence. (A) Fluorescence yields at 687 and $760 \mathrm{~nm}$ and PAR plotted versus time (June 6th). (B) Fluorescence yield at $687 \mathrm{~nm}$ (June 6th) plotted versus incident light and the curve obtained by an exponential fit. (C) Comparison of the fitted curves at 687 and $760 \mathrm{~nm}$ for a day at the beginning of the campaign, May 6th, and a day at the end of the campaign, June 6th. The initial tangents are represented for the curves at $760 \mathrm{~nm}$.
Table 1

Chlorophyll, xanthophyll cycle carotenoids and lutein content, at the beginning (May 8th) and at the end (June 12th) of the campaign

\begin{tabular}{lllll}
\hline & $\begin{array}{l}\text { Chl a+Chl b } \\
(\mu \mathrm{g} / \mathrm{g} \mathrm{DW})\end{array}$ & Chl a / Chl b & $\begin{array}{l}\text { Xanthophyll pool } \\
(\mu \mathrm{g} / \mathrm{g} \mathrm{DW})\end{array}$ & $\begin{array}{l}\text { Lutein } \\
(\mu \mathrm{g} / \mathrm{g} \mathrm{DW})\end{array}$ \\
\hline May 8th & 2500 & 3.1 & 86.7 & 141 \\
June 12th & 2900 & 3.4 & 60.6 & 92.5 \\
\hline
\end{tabular}

non-photochemical quenching and this contribution is diluted in the overall fluorescence emission of the canopy.

\subsection{Evolution of the signals during spring recovery}

The structural effects make the interpretation of the diurnal cycles of the passive measurements more difficult. However the calculation of time series alleviates this problem and reveals the evolution of the fluorescence signals during spring recovery. The time series obtained with the PMFD (Fig. 8) show that the fluorescence yields variations were parallel to the PAR variations: this is a typical characteristic of plants under weak constraints. On the other hand, the negative correlation of $\Delta \mathrm{F} / \mathrm{Fm}$ ' with the PAR, observed for active measurements (Fig. 11) is rather indicative of a light constraint. Again this may be explained by the structural effects and the difference in the illumination of the target, as already discussed.

Considering the temporal evolution of fluorescence yields, we observed that $\Phi F 687$ stayed almost constant during the campaign, while $\Phi F 760$ increased, particularly at the end of the campaign. The increase of $\Phi F 760$ could be related to the increase of the $\mathrm{Chl}$ content during the campaign (see Table 1). One can hypothesize that the fluorescence flux is proportional to the absorbed PAR, which depends on the total $\mathrm{Chl}$ amount. As the fluorescence at $760 \mathrm{~nm}$ is not re-absorbed by the Chl, we expected an increase when the $\mathrm{Chl}$ amount increases (Gitelson et al., 1999). The situation is different at $687 \mathrm{~nm}$, which is a wavelength strongly absorbed. In that case, F687 is saturated even for low $\mathrm{Chl}$ concentrations. As a result we do not expect any increase of $\Phi F 687$, in agreement with the observation. The effect of the $\mathrm{Chl}$ concentration increase is better evidenced on the F687/F760 ratio which exhibited a continuous decrease, more marked at the end of the campaign (Fig. 8B). No significant change was observed on the temporal evolution of the NDVI index (not shown), indicating a lower sensitivity of this index compared to fluorescence.

Fig. 12C shows the dynamical response of Chl fluorescence to the variations of incident light. This response contains the variations of the $\mathrm{Chl}$ fluorescence yields in response to the change of ambient light and also fluorescence induction transitions occurring after very rapid light changes. The increase of the initial slope $(\Delta \mathrm{F} / \Delta \mathrm{PAR})$ between the beginning and the end of the campaign is interpreted as a reduction of the mechanisms of non radiative energy dissipation, which maintain a low $\mathrm{Chl}$ 
fluorescence yield under cold acclimated conditions. In addition to $\Delta \mathrm{pH}$ associated NPQ, these mechanisms include long-term sustained quenching for the whole winter period (Öquist \& Huner, 2003). This last quenching mechanism affects both radiative and photochemical energy dissipation pathways. It is well documented that a plant under constraint is often characterized by a lower light threshold for the apparition of the NPQ. As a result, a lower Fs is observed for a given light level (Cerovic et al., 1996; Flexas et al., 2000; Günther et al., 1994). However in the present case, the change observed during the campaign concerns mainly the long-term quenching associated with cold acclimation.

Although active and passive measurements were performed with different targets and illumination conditions, the fluorescence parameters measured with these two techniques reveal the same evolution during the campaign. Indeed, the time series obtained with the FIPAM confirmed the previous conclusion. Fig. 11 shows an increasing level of the maximal photochemical yield $(\mathrm{Fv} / \mathrm{Fm})$ and hence an increase of the photosynthetic activity. These findings were corroborated by the time series of the net $\mathrm{CO}_{2}$ assimilation (Fig. 10). The effective electron transfer rate $(\Delta \mathrm{F} / \mathrm{Fm})$, that was measured continuously during the campaign, also shows the same trend. It is necessary for this to consider separately low light and high light conditions as shown in Fig. 11.

One can conclude that interesting information on the photosynthetic capacity of the vegetation is contained in naturally-induced fluorescence variations, which can be accessed by passive fluorescence remote sensing.

Another interesting result is the good correlation between the PRI index and the net $\mathrm{CO}_{2}$ assimilation (Fig. 10). The PRI index is associated with two identified mechanisms, involved in excess light dissipation as heat. The first one corresponds to rapid changes in the aggregation state of antenna chlorophyll-protein complexes induced by the energisation of the thylakoid membrane. It is accompanied by absorbance changes centered near 531$535 \mathrm{~nm}$ (Bilger et al., 1989; Ruban et al., 1993). The second one corresponds to the dynamic changes in the deepoxidation state of the xanthophyll cycle, which are accompanied by absorbance changes at 505-515 nm (Bilger et al., 1989; Heber, 1969; Heber et al., 1986; Krause, 1973; Li et al., 2000). The absorption changes generate a broad reflectance change around $531 \mathrm{~nm}$, including both mechanisms (Gamon et al., 1990). The robustness of this correlation was strengthened in a recent work on grape vines (Evain et al., 2004), which demonstrated the existence of two phases. A rapid phase lasting less than $2 \mathrm{~s}$ consists in a sudden drop of PRI immediately after a steep increase in light intensity. A slow phase of adjustment, after the initial rapid phase, lasts several minutes. The rapid phase is probably ascribable to chloroplast shrinkage following an increase of $\Delta \mathrm{pH}$ and partly due to the non-photochemical quenching involving de-epoxidated xanthophylls; the slow phase is related to the latter phenomenon. Importantly, it has been proposed by Öquist and Huner (2003) that cold acclimation transforms the xanthophyll-mediated non-photochemical antenna quenching of absorbed light from a short-term dynamic response to a long-term sustained quenching for the whole winter period. This was supported by Ottander et al. (1995) who showed that the carotenoid content of Scots pine needles is subject to important accumulation during the cold season followed by a decrease when the full photosynthetic capacity is recovered in June. These changes were associated with a major reorganisation of the light-harvesting complexes. The pigment analysis conducted for this campaign confirmed a decrease of the carotenoid pool and especially of the lutein pigment during spring recovery. The good correlation found between the PRI and the net $\mathrm{CO}_{2}$ assimilation would imply that PRI is also sensitive to this long-term sustained quenching. The steep increase of PRI in June correlates with the relaxation of that NPQ, and thus with the increase of the Scots pine photosynthetic activity.

The instrument required for the measurement of the PRI index is much simpler than that needed for measurement of $\mathrm{CO}_{2}$ assimilation. PRI would then be an interesting alternative for the monitoring of photosynthetic activity at the tree canopy scale, over wide area.

The results presented here show that passive fluorescence remote sensing is now possible at the canopy level, at large distances and over a long period, even with cloudy weather. The 687/760 fluorescence ratio evolved parallel to the Chl content and a dynamical study of fluorescence showed the increase of photochemical activity. However, as the fluorescence signals strongly depend on structural effects, modeling will be necessary for further interpretation.

\section{References}

Adams, W. W., III, \& Demmig-Adams, B. (1994). Carotenoid composition and down regulation of photosystem II in three conifer species during the winter. Physiologia Plantarum, 92, 451-458.

Apostol, S., Briantais, J. -M., Moise, N., Cerovic, Z. G., \& Moya, I. (2001). Photoinactivation of the photosynthetic electron transport chain by accumulation of over-saturating light pulses given to dark adapted pea leaves. Photosynthesis Research, 67, 215-227.

Aurela, M., Laurila, T., \& Tuovinen, J. -P. (2001). Seasonal CO2 balances of a subarctic mire. Journal of Geophysical Research, 106(D2), $1623-1638$.

Aurela, M., Laurila, T., \& Tuovinen, J. -P. (2002). Annual $\mathrm{CO}_{2}$ balance of a subarctic fen in northern Europe: The importance of the wintertime efflux. Journal of Geophysical Research, 107(D21), 1-12.

Bilger, W., Björkman, O., \& Thayer, S. S. (1989). Light-induced spectral absorbance changes in relation to photosynthesis and the epoxidation state of xanthophyll cycle components in cotton leaves. Plant physiology, 91, 542-551.

Cerovic, Z. G., Goulas, Y., Gorbunov, M., Briantais, J. -M., Camenen, L., \& Moya, I. (1996). Fluorosensing of water stress in plants. Diurnal changes of the mean lifetime and yield of chlorophyll fluorescence, measured simultaneously and at distance with a t-LIDAR and a modified PAM-fluorimeter, in maize, sugar beet and Kalanchoë. Remote Sensing of Environment, 58, 311-321. 
Demmig-Adams, B., \& Adams, W. W. I. (1992). Photoprotection and other responses of plants to high light stress. Annual Review of Plant Physiology and Plant Molecular Biology, 43, 599-626.

Evain, S., Camenen, L., \& Moya, I. (2001). Three channels detector for remote sensing of chlorophyll fluorescence and reflectance from vegetation, 8th international symposium: Physical measurements and signatures in remote sensing, Aussois, France, CNES, M. Leroy (pp. 395-400).

Evain, S., Flexas, J., \& Moya, I. (2004). A new instrument for passive remote sensing: 2. Measurement of leaf and canopy reflectance changes at $531 \mathrm{~nm}$ and their relationship with photosynthesis and chlorophyll fluorescence. Remote Sensing of Environment, 91, 175-185.

Flexas, J., Briantais, J. -M., Cerovic, Z. G., Medrano, H., \& Moya, I. (2000). Steady-state and maximum chlorophyll fluorescence responses to water stress in grapevine leaves: A new remote sensing system. Remote Sensing of Environnment, 73, 283-297.

Gamon, J. A., Field, C. B., Bilger, W., Björkman, O., Fredeen, A. L., \& Penuelas, J. (1990). Remote sensing of xanthophyll cycle and chlorophyll fluorescence in sunflower leaves and canopies. Oecologia, $85,1-7$.

Gilmore, A. M., \& Ball, M. C. (2000). Protection and storage of chlorophyll in overwintering evergreens. Proceedings of the National Academy of Sciences, 97, 11098-11101.

Gitelson, A. A., Buschmann, C., \& Lichtenthaler, H. K. (1999). The chlorophyll fluorescence ratio F735/F700 as an accurate measurement of the chlorophyll content in plants. Remote Sensing of Environment, 69, 296-302.

Günther, K. P., Dahn, H. -G., \& Lüdeker, W. (1994). Remote sensing vegetation status by laser-induced fluorescence. Remote Sensing of Environment, 47, 10-17.

Hapke, B., DiMucci, D., Nelson, R., \& Smythe, W. (1996). The cause of the hot spot in vegetation canopies and soils: Shadow-hiding versus coherent backscatter. Remote Sensing of Environment, 58, 63-68.

Heber, U. (1969). Conformational changes of chloroplasts induced by illumination of leaves in vivo. Biochimica et Biophysica Acta, 180, $302-319$.

Heber, U., Neimanis, S., \& Lange, O. L. (1986). Stomatal aperture, photosynthesis and water fluxes in mesophyll cells as affected by the abscission of leaves. Simultaneous measurements of gas exchange, light scattering and chlorophyll fluorescence. Planta, 167, 554-562.
Ivanov, A. G., Sane, P., Zeilanov, Y., Malmberg, G., Gardeström, P., Huner, N. P. A., et al. (2001). Photosynthetic electron transport adjustments in overwintering Scots pine (Pinus sylvestris L.). Planta, 213, 575-585.

Krause, G. H. (1973). The high-energy state of the thylakoid system as indicated by chlorophyll fluorescence and chloroplast shrinkage. Biochimica et Biophysica Acta, 292, 715-728.

Kuusk, A. (1985). The hot spot effect of a uniform vegetative cover. Soviet Journal of Remote Sensing, 3, 645-658.

Li, X. -P., Björkman, O., Shih, C., Grossman, A. R., Rosenquist, M., Jansson, S., et al. (2000). A pigment-binding protein essential for regulation of photosynthetic light harvesting. Nature, 403, 391-395.

Moya, I., Camenen, L., Evain, S., Goulas, Y., Cerovic, Z. C., Latouche, G., et al. (2004). A new instrument for passive remote sensing: 1. Measurements of sunlight induced chlorophyll fluorescence. Remote Sensing of Environment, 91, 186-197.

Moya, I., Camenen, L., Latouche, G., Mauxion, C., Evain, S., \& Cerovic, Z. G. (1998). An instrument for the measurement of sunlight excited plant fluorescence. Photosynthesis: Mechanisms and effects (pp. 4265-4270). G. Garab, Dordrecht: Kluwer Academic Pub., V.

Niyogi, K. K. (1999). Photoprotection revisited: Genetic and molecular approaches. Annual Review of Plant Physiology and Plant Molecular Biology, 50, 333-359.

Öquist, G., \& Huner, N. P. A. (2003). Photosynthesis of overwintering evergreen plants. Annual Review of Plant Biology, 54, 329-355.

Ottander, C., Douglas, C., \& Öquist, G. (1995). Seasonal changes in photosystem II organisation and pigment composition in Pinus sylvestris. Planta, 197, 176-183.

Plascyk, J. A. (1975). The MK II Fraunhofer line discriminator (FLD-II) for airborne and orbital remote sensing of solar-stimulated luminescence. Optical Engineering, 14, 339-346.

Plascyk, J. A., \& Gabriel, F. C. (1975). The Fraunhofer line discriminator MKII-An airborne instrument for precise and standardized ecological luminescence measurements. IEEE Transactions on Instrumentation and Measurement, 24, 306-313.

Ruban, A. V., Horton, P., \& Young, A. J. (1993). Aggregation of higher plant xanthophylls - differences in absorption spectra and in the dependency on solvent polarity. Journal of Photochemistry and Photobiology, B, Biology, 21, 229-234.

Tucker, C. J. (1979). Red and photographic infrared linear combination for monitoring vegetation. Remote Sensing of Environment, 8, 127-150. 